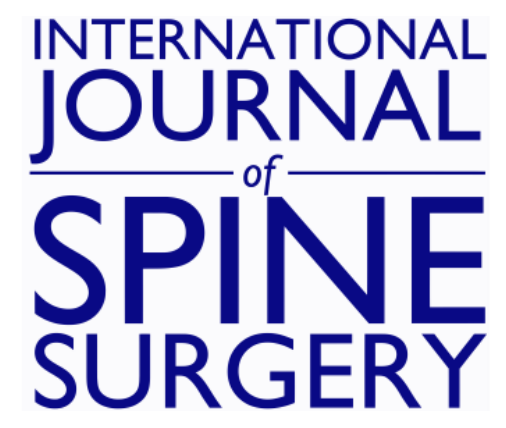

\title{
Placement of C1 Pedicle Screws Using Minimal Exposure: Radiographic, Clinical, and Literature Validation
}

Richard P. Menger, Christopher M. Storey, Menarvia K.C. Nixon, Justin Haydel, Anil Nanda and Anthony Sin

Int J Spine Surg 2015, 9 ()

doi: https://doi.org/10.14444/2043

http://ijssurgery.com/content/9/43

This information is current as of April 26, 2023.

Email Alerts Receive free email-alerts when new articles cite this article. Sign up at:

http://ijssurgery.com/alerts

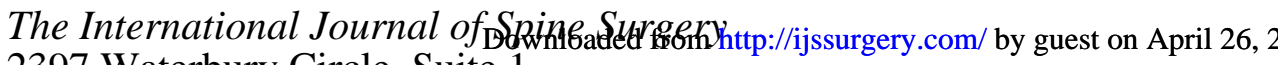
2397 Waterbury Circle, Suite 1,

Aurora, IL 60504, Phone: +1-630-375-1432

(C) 2015 ISASS. All Rights Reserved. 


\section{Placement of C1 Pedicle Screws Using Minimal Exposure: Radiographic, Clinical, and Literature Validation}

Richard P. Menger, MD, Christopher M. Storey, MD, PhD, Menarvia K.C. Nixon, MD, Justin Haydel, MD, Anil Nanda, MD, MPH, FACS, Anthony Sin $M D$

Department of Neurosurgery, Louisiana State University of Health Sciences, Shreveport LA

\section{Abstract}

Background

Traditional C1-2 fixation involves placement of $\mathrm{C} 1$ lateral mass screws. Evolving techniques have led to the placement of $\mathrm{C} 1$ pedicle screws to avoid exposure of the $\mathrm{C} 1-\mathrm{C} 2$ joint capsule. Our minimal dissection technique utilizes anatomical landmarks with isolated exposure of $\mathrm{C} 2$ and the inferior posterior arch of $\mathrm{C} 1$. We evaluate this procedure clinically and radiographically through a technical report.

Methods

Consecutive cases of cranial-vertebral junction surgery were reviewed for one fellowship trained spinal surgeon from 2008-2014. Information regarding sex, age, indication for surgery, private or public hospital, intra-operative complications, post-operative neurological deterioration, death, and failure of fusion was extracted. Measurement of pre-operative axial and sagittal CT scans were performed for $\mathrm{C} 1$ pedicle width and $\mathrm{C} 1$ posterior arch height respectively.

Results

64 patients underwent posterior cranio-vertebral junction fixation surgery. 40 of these patients underwent occipital-cervical fusion procedures. $7 / 9(77.8 \%) \mathrm{C} 1$ instrumentation cases were from trauma with the remaining two (22.2\%) from oncologic lesions. The average blood loss among isolated C1-C2 fixation was 160cc. 1/9 patients (11.1\%) suffered pedicle breech requiring sub-laminar wiring at the $\mathrm{C} 1$ level.

On radiographic measurement, the average height of the $\mathrm{C} 1$ posterior arch was noted at $4.3 \mathrm{~mm}$ (range $3.8 \mathrm{~mm}$ to $5.7 \mathrm{~mm}$ ). The average width of the $\mathrm{C} 1$ pedicle measured at $5.3 \mathrm{~mm}$ (range 2.8 to $8.7 \mathrm{~mm}$ ). The patient with $\mathrm{C} 1$ pedicle screw failure had a pedicle width of $2.78 \mathrm{~mm}$ on pre-operative axial CT imaging.

\section{Conclusion}

Our study directly adds to the literature with level four evidence supporting a minimal dissection of $\mathrm{C} 1$ arch in the placement of $\mathrm{C} 1$ pedicle screws with both radiographic and clinical validation.

\section{Clinical Relevance}

Justification of this technique avoids $\mathrm{C} 2$ nerve root manipulation or sacrifice, reduces bleeding associated with the venous plexus, and leaves the third segment of the vertebral artery unexplored. Pre-operative review of imaging is critical in the placement of C1-C2 instrumentation.

KEYWORDS: C1-C2 INSTRUMENTATION, LATERAL MASS SCREW, PEDICLE SCREW, PARS INTERARTICULARIS SCREW

VOLUME 9 ARTICLE 43 DOI: 10.14444/2043

\section{Introduction}

Atlanto-axial instability can have devastating consequences when not treated effectively. A wide range of causes can be fixated posteriorly including: traumatic, inflammatory, neoplastic, iatrogenic, congenital, or infectious processes ${ }^{1,2}$ Historical techniques have varied from wiring to screw instrumentation involving the pars interarticularis or pedicle of $\mathrm{C} 2$ and the lateral mass of $\mathrm{C} 1 .^{3}$ Traditional C1-C2 fusion techniques require extensive dissection of the $\mathrm{C} 1-\mathrm{C} 2$ joint capsule that disrupts the venous plexus, puts the $\mathrm{C} 2$ nerve root at risk, and exposes the vertebral artery. Adding complexity, variation of the vertebral 
artery course is seen in approximately $20 \%$ of patients. $^{4}$

The $\mathrm{C} 1$ pedicle screw technique involves the placement of $\mathrm{C} 1$ fixation without extensive dissection of the C1-C2 joint capsule. At its inception, this technique was performed with stereotactic guidance but advances have proven this method safe with fluoroscopy. ${ }^{4,5}$ Our technique requires minimum dissection of the $\mathrm{C} 1 \mathrm{arch}$ in the placement of notched $\mathrm{C} 1$ pedicle screws. Typical technique for $\mathrm{C} 1$ pedicle screw placement focuses on intraoperative estimation of the $\mathrm{C} 1$ pedicle entry point as $2 \mathrm{~cm}$ lateral from midline and $2 \mathrm{~mm}$ from the inferior border of the posterior arch. ${ }^{3,6}$ Traditional dissection is carried wide enough for palpation of medial and lateral borders and possible mobilization of the vertebral artery. Our series uses the mid-point of the $\mathrm{C} 2$ lateral mass as the medial-lateral landmark for the entry point of notched $\mathrm{C} 1$ pedicle screw and places the screw in the inferior lip of the $\mathrm{C} 1$ posterior arch.. This avoids unnecessary dissection, blood loss, and supplements direct visualization of entry point while utilizing lateral fluoroscopy to define the superior-inferior trajectory. We present our data as a technical report, examining both radiographic and clinical considerations.

\section{Material and Methods}

Operative technique

After obtaining baseline neuro-monitoring, the patient is then placed in a prone position on a spinal operative table. The patient is placed in Gardner-Wells tongs with 15 pounds of traction. Gel rolls are used to obtain mobility for positioning with flexion and extension. Three-point cranial pinning is used in cases undergoing occipital-cervical fusion. Attention is placed to avoid excessive flexion (swallowing issues) and extension specifically in occipital-cervical fusion cases. The prominent spinous process of $\mathrm{C} 2$ and $\mathrm{C} 7$ are then palpated with the incision marking the anatomical landmarks for required levels of fusion. The incision is carried out with combination of knife, monopolar, and bipolar cautery with great care taken to stay in the nuchal line. The spinous process of $\mathrm{C} 2$ is appreciated with sub-periosteal dissection taken to the lateral border of the lateral mass of $\mathrm{C} 2$ and any points inferior. A C2 pars interarticularis screw is then placed using standard anatomical landmarks. The entry point for the $\mathrm{C} 2$ pars screws is $3 \mathrm{~mm}$ rostral and $3 \mathrm{~mm}$ lateral to the inferior medial aspect of the inferior articular surface of C2. Exposure illustrates the medial and lateral borders of the pars interarticularis. The depth is measured pre-operatively on CT imaging but also noted on fluoroscopy. Cranialcaudal direction is obtained based on lateral fluoroscopy following the trajectory of the pars interarticularis. Attention is then turned to placement of a notched $\mathrm{C} 1$ pedicle screw. No additional dissection is performed beyond the inferior ring of $\mathrm{C} 1$ lamina. The landing zone is noted on the inferior border of the $\mathrm{C} 1$ lamina. This is replicated in Figure 1 and Figure 2 . The vertebral artery is not mobilized. The screw is placed directly superior to the mid-point of the $\mathrm{C} 2$ lateral mass. The cranial-caudal direction is then obtained on lateral fluoroscopy with stopping point noted to be just behind the anterior tubercle of C1. The standard 10-degree medialization is maintained in screw trajectory. Axial screw trajectory can be appreciated in Figure 3. The rods and set screws are placed in a standard fashion with bone, bone product, and decortication. This is illustrated in Figure 4 and Figure 5.

\section{Clinical Review}

Consecutive cranial-vertebral junction surgeries were reviewed for one fellowship trained spinal surgeon operating at both a private and academic hospital from 2008-2014. Surgery was defined as posterior cranial-vertebral junction surgery if instrumentation was placed in the occiput, $\mathrm{C} 1$, or $\mathrm{C} 2$ vertebra. Infor-

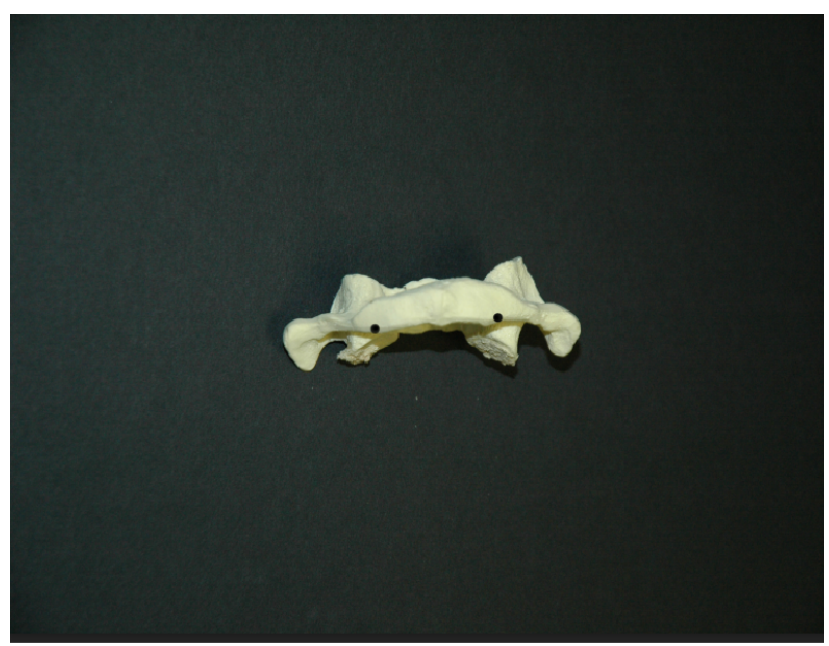

Fig. 1. Coronal C1 Pedicle Screw Entry Point.

Downloaded from http://ijssurgery.com/ by guest on April 26, 2023 


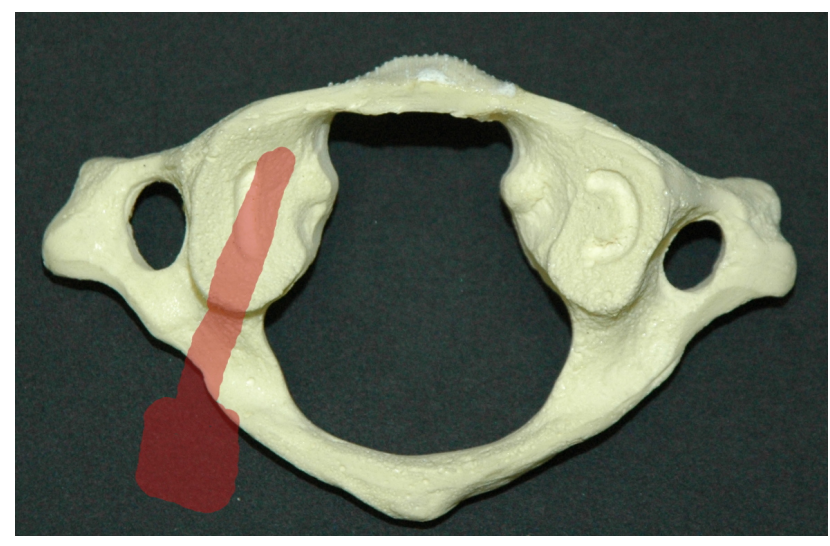

Fig. 2. Axial C1 Pedicle Screw Entry Point.

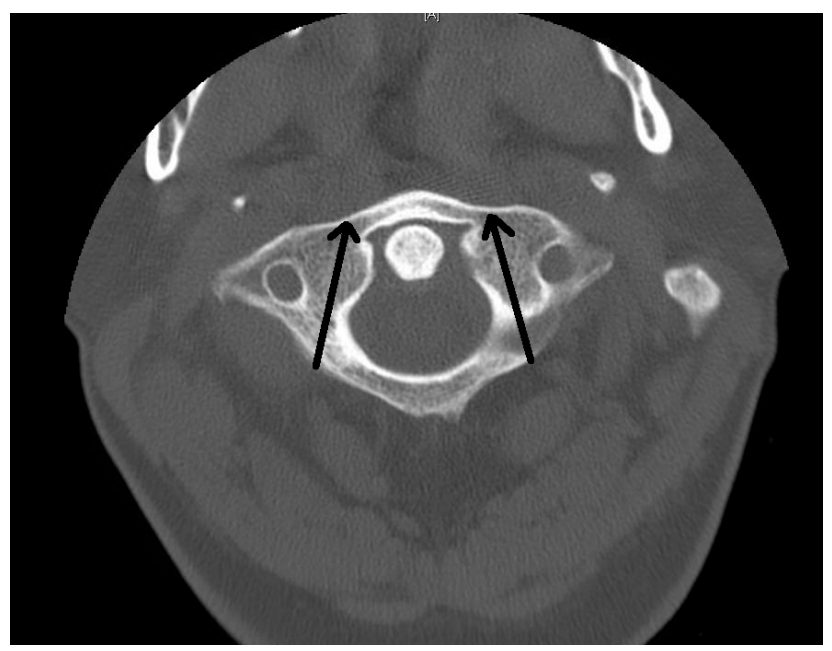

Fig. 3. Axial Trajectory of $\mathrm{C} 1$ Pedicle Screw.

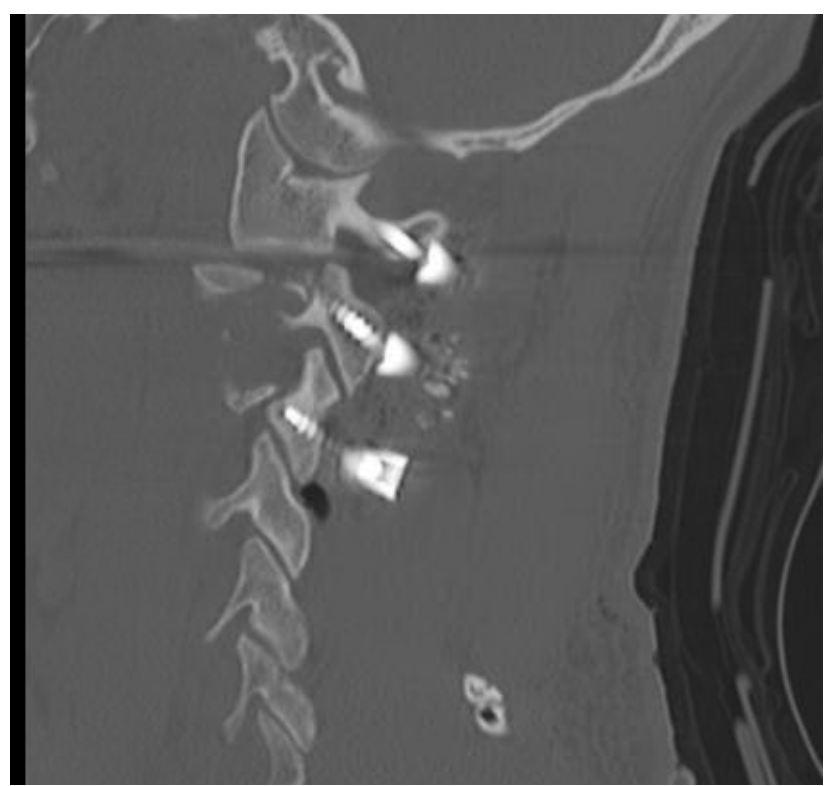

Fig. 4. Sagittal CT Illustrating C1-2-3 Fixation with C1 Pedicle Screw Technique. mation regarding sex, age, indication for surgery, private or public hospital, intra-operative complications, post-operative neurological deterioration, death, and failure of fusion was extracted. Breech of the $\mathrm{C} 1$ screw was determined by operative note dictation and post-operative construct. Information was extracted using the neurosurgical spine database at Louisiana University Health Sciences Center Shreveport. Further detail was noted from patient charts available for retrospective review. Internal Review Board approval was obtained under H13-020.

\section{Radiographic Review}

Patients who underwent $\mathrm{C} 1$ instrumentation had $\mathrm{C} 1$ posterior ring height and pedicle width measured on sagittal and axial CT imaging respectively. The ring of $\mathrm{C} 1$ was measured from its inferior ledge to the vertebral groove using the smallest diameter recording. Sagittal imaging was used secondary to its better estimate of the vertebral groove on the superior aspect of the ring of $\mathrm{C} 1$. Pedicle width was measured on axial CT scan by calculating the distance at the screw entry-landing zone, the outermost portion of the $\mathrm{C} 1$ ring that will be within the screw's trajectory.

\section{Results}

From 2008 to 2014, 64 patients underwent posterior

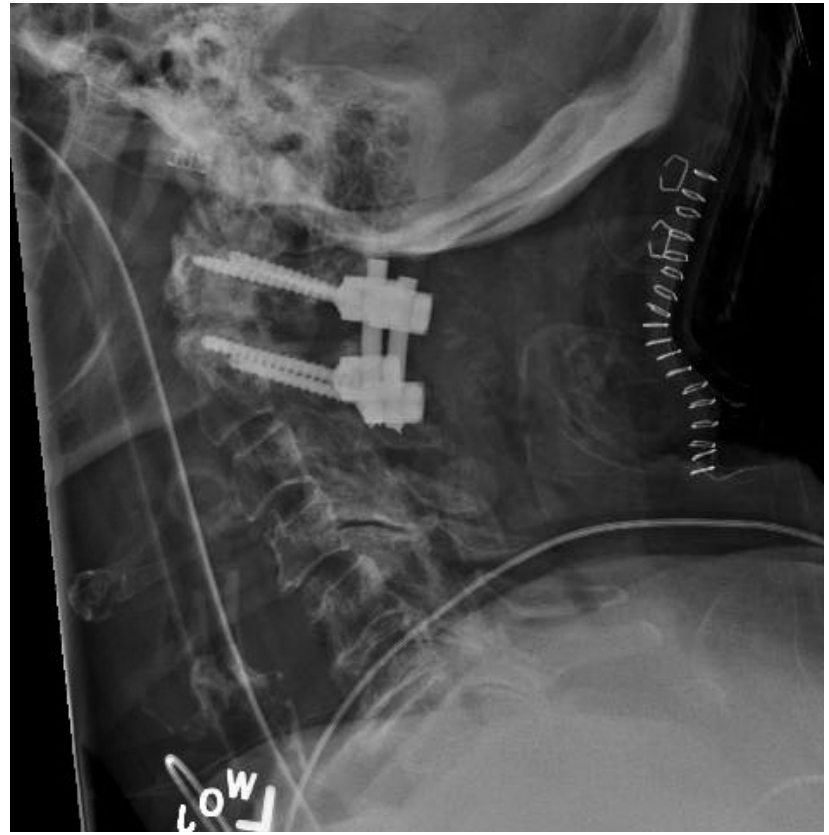

Fig. 5. Post-operative Lateral Cervical X-ray Showing C1-2 Pedicle Screw Fixation 
cranio-vertebral junction instrumentation surgery. Forty of 64 (62.5\%) of these patients underwent occipital-cervical fusion procedures. Fifteen of 64 (23.4\%) of patients underwent the placement of $\mathrm{C} 2$ pars interarticularis screws in conjunction with cervical or thoracic fusion. 9 patients underwent specific $\mathrm{C} 1$ instrumentation using the notched pedicle technique. This represents only $14.1 \%$ (9/64) of all cranio-vertebral junction surgery in our series (Table 1).

Seven of nine (77.8\%) C1 instrumentation cases were secondary to trauma with the remaining two $(22.2 \%)$ from oncologic lesions. No C1 screws were placed for rheumatoid or degenerative disease. Five cases involving $\mathrm{C} 1$ fixation were for isolated $\mathrm{C} 1-2$ fusion. Four cases involving $\mathrm{C} 1$ fixation extended the level of fusion to thoracic or other cervical levels. The average blood loss among isolated C1-C2 fixation surgeries was $160 \mathrm{cc}$ (range 100-300cc). One of 9 patients (11.1\%) suffered pedicle breech requiring sub-laminar wiring at the $\mathrm{C} 1$ level. This represents a failure in $1 /$ 17 pedicles (5.9\%). The contralateral pedicle of the failure patient was not attempted. No deaths occurred. No neurological decline was noted in the immediate post-operative period. No cases of postoperative occipital neuralgia were reported. No patients, over at least a 6-month follow up period, have required revision surgery. No vertebral artery injuries were found. Table 2 illustrates descriptive data for specific atlanto-axial cases including radiographic measurements.

On radiographic measurement, the average height of the posterior arch was noted at $4.3 \mathrm{~mm}$ (range $3.8 \mathrm{~mm}$ to $5.7 \mathrm{~mm}$ ). The average width of the $\mathrm{C} 1$ pedicle measured at $5.3 \mathrm{~mm}$ (range 2.8 to $8.7 \mathrm{~mm}$ ). Failure to adequately place $\mathrm{C} 1$ pedicle screw was seen in the patient with a pedicle width of $2.78 \mathrm{~mm}$.

Table 1. 64 Patients Undergoing Cranio-vertebral Junction Instrumentation.
\begin{tabular}{|l|l|}
\hline Procedure & Case \\
\hline Occipital-Cervical Fusion & 40 \\
\hline C2-to cervical or thoracic fusion & 15 \\
\hline C1 to cervical or thoracic fusion & 4 \\
\hline C1-C2 fixation & 5 \\
\hline
\end{tabular}

\section{Discussion}

Over the past several decades, rigid C1-2 fixation has become increasingly advocated due to its high fusion rates and stability in all planes. The final target point for a proper trajectory is the anterior tubercle of $\mathrm{C} 1$ as visualized on a lateral fluoroscopic image. The entry point for the $\mathrm{C} 1$ lateral mass screw has traditionally identified at the center of the $\mathrm{C} 1$ lateral mass. Using fluoroscopy, a $3 \mathrm{~mm}$ drill bit and guide are used to drill a hole with 10-15 degrees medial angulation aimed towards the anterior tubercle of $\mathrm{C} 1{ }^{3,8,10}$ We however, suggest, minimal dissection through placement of a $\mathrm{C} 1$ pedicle screw as safe and effective for the fixation of the $\mathrm{C} 1$ vertebra in patients with adequate evaluation of pre-operative CT imaging.

\section{C1 Pedicle Screw}

We essentially investigated specific $\mathrm{C} 1$ lateral mass screws placed via the posterior arch, $\mathrm{C} 1$ pedicle screws. $\mathrm{C} 1$ lateral mass screws are more comman than $\mathrm{C} 1$ pedicle screws due to increased theoretical risk of vertebral artery injury. However, Yeom et al. showed that $\mathrm{C} 1$ pedicle can be safely placed in routine practice. ${ }^{11}$ Thomas et al. describe a series of 26 patients who had $\mathrm{C} 1$ pedicle screws with good clinical outcomes. ${ }^{4,11}$ No vertebral artery injuries were reported in any of these series utilizing pedicle or notched technique. ${ }^{12}$

Obstacles of $\mathrm{C} 1$ pedicle screws are similar to that of lateral mass screws: vertebral artery injury, persistent 1st intersegmental artery injury, hypoglossal nerve injury, internal carotid artery injury, and occipital neuralgia. The other unique difficulty is having adequately sized pedicles to contain the $3.5-4 \mathrm{~mm}$ diameter screws. However, an isolated caudal or cranial pedicle breach is not worrisome since the purchase in the lateral mass remains identical to that of $\mathrm{C} 1$ lateral mass screws. Yeom et al. showed that even vertical splitting did not affect purchase since fracture line did not extend to the lateral mass. ${ }^{11}$

The height of the $\mathrm{C} 1$ pedicle on average ranges from $3.95 \mathrm{~mm}$ to $4.8 \mathrm{~mm}$. ${ }^{6,11,13,14,15,16} \mathrm{Up}$ to $53.8 \%$ of people have a posterior arch height of less than $4 \mathrm{~mm} .{ }^{15}$ Both Lee et al. and Qian et al. have shown that women have a significantly lower outer cortical height than 
men so extra care should be taken when considering $\mathrm{C} 1$ pedicle screws in the female population. ${ }^{14,15}$ However, the anatomy of the atlas does present landmarks to be utilized intraoperatively. Tan et al. showed the optimal entry point is $2 \mathrm{~cm}$ from midline and $2 \mathrm{~mm}$ from inferior border of posterior arch. ${ }^{13}$ The superior surface of the $\mathrm{C} 1$ posterior arch is more variable and should not be used screw placement. ${ }^{13}$

Benefits are that $\mathrm{C} 1$ pedicle screw does not require extensive dissection to expose the $\mathrm{C} 1$ lateral mass for screw placement. Decreased occipital neuralgia and blood loss has been noted. ${ }^{17}$ Yeom et al. did note postoperative occipital neuralgia due to extensive dissection and retraction for articular fusion. However, this resolved spontaneously except for a single case of transection. ${ }^{11}$ Of importance, Lin et al. does caution that anatomic variability in the posterior elements of the atlas requires extensive review of preoperative CT imaging for safe screw placement. ${ }^{18}$

\section{Patient Outcomes}

Our series illustrates the relative paucity of $\mathrm{C} 1$ instrumentation in the context of isolated atlanto-axial instrumentation. This represents only 14.1\% (9/64) of all cranio-vertebral junction surgery in our series. Seven of 9 (77.8\%) C1 instrumentation cases were from trauma with the remaining two $(22.2 \%)$ from oncologic lesions. In our series, this included disruption of the transverse longitudinal ligament as well as non-healing type 2 odontoid fractures or odontoid screw placement prohibited by body habitus. Overhang of $\mathrm{C} 1$ lateral masses on $\mathrm{C} 2$ by $7.0 \mathrm{~mm}$ of greater also illustrates the need for $\mathrm{C} 1$ instrumentation. ${ }^{2} \mathrm{Al}-$ though, not seen in our series, in the setting of rheumatoid arthritis, improved outcomes have been seen with fixation with posterior atlanto-dens interval $>14 \mathrm{~mm} .{ }^{2}$ Fixation may have to be extended to occiput due to basilar invagination. Indications for occipital-cervical fusion generally prohibit the placement of $\mathrm{C} 1$ instrumentation secondary to technical logistics of rod placement. Indeed in our series, only one patient with specific C1-2 subluxation underwent both $\mathrm{C} 1$ instrumentation and occipital-cervical fusion.

Our technique was met with limited blood loss of less than $300 \mathrm{cc}$ in all patients. The average blood loss for

Table 2. Patients Undergoing C1 Pedicle Screw Fixation.

\begin{tabular}{|c|c|c|c|c|c|c|c|}
\hline Patient & Procedure & Indication & Presentation & $\begin{array}{l}\text { C1 Pedicle Screw } \\
\text { Outcome }\end{array}$ & $\begin{array}{l}\text { Blood loss } \\
(\mathrm{C} 1-\mathrm{C} 2)\end{array}$ & $\begin{array}{l}\text { C1 Posterior Arch } \\
\text { Height }\end{array}$ & $\begin{array}{l}\text { C1 Pedicle } \\
\text { Width }\end{array}$ \\
\hline $73 \mathrm{~F}$ & $\begin{array}{l}\mathrm{C} 1-\mathrm{T} 2 \\
\text { fusion }\end{array}$ & Oncologic & $\mathrm{C} 2$ and $\mathrm{C} 7$ met & Successful & - & $3.8 \mathrm{~mm}$ & $\begin{array}{l}\mathrm{R} 4.11 \mathrm{~mm} \\
\mathrm{~L} 4.06 \mathrm{~mm}\end{array}$ \\
\hline $22 \mathrm{M}$ & C1-2 fusion & Trauma & C1-2 distraction & Successful & $100 \mathrm{cc}$ & $4.13 \mathrm{~mm}$ & $\begin{array}{l}\text { R } 5.16 \mathrm{~mm} \\
\mathrm{~L} 4.89 \mathrm{~mm}\end{array}$ \\
\hline $76 \mathrm{~F}$ & $\begin{array}{l}\text { O-T1 } \\
\text { fusion }\end{array}$ & Trauma & C1-2 sublux & Successful & - & $4.43 \mathrm{~mm}$ & $\begin{array}{l}\mathrm{R} 4.06 \mathrm{~mm} \\
\mathrm{~L} 5.23 \mathrm{~mm}\end{array}$ \\
\hline $78 \mathrm{~F}$ & C1-2 fusion & Trauma & Type II Odontoid & Successful & $200 \mathrm{cc}$ & $4.29 \mathrm{~mm}$ & $\begin{array}{l}\mathrm{R} 4.20 \mathrm{~mm} \\
\mathrm{~L} 4.53 \mathrm{~mm}\end{array}$ \\
\hline $67 \mathrm{M}$ & C1-4 fusion & Oncologic & C2 metastatic & Successful & - & $4.7 \mathrm{~mm}$ & $\begin{array}{l}\text { R } 5.4 \mathrm{~mm} \\
\text { L } 5.9 \mathrm{~mm}\end{array}$ \\
\hline $31 \mathrm{M}$ & C1-3 fusion & Trauma & $\mathrm{C} 2$ fracture & Successful & - & $5.67 \mathrm{~mm}$ & $\begin{array}{l}\text { R } 8.70 \mathrm{~mm} \\
L 7.61 \mathrm{~mm}\end{array}$ \\
\hline $73 \mathrm{M}$ & C1-2 fusion & Trauma & Type II Odontoid & Successful & $100 \mathrm{cc}$ & $4.1 \mathrm{~mm}$ & $\begin{array}{l}\text { R } 6.7 \mathrm{~mm} \\
\mathrm{~L} 6.6 \mathrm{~mm}\end{array}$ \\
\hline $83 \mathrm{~F}$ & C1-2 fusion & Trauma & Type II Odontoid & Successful & $100 \mathrm{cc}$ & $3.9 \mathrm{~mm}$ & $\begin{array}{l}\text { R } 5.0 \mathrm{~mm} \\
\text { L } 5.2 \mathrm{~mm}\end{array}$ \\
\hline $35 \mathrm{M}$ & C1-2 fusion & Trauma & $\begin{array}{l}\text { Odontoid screw failure, Old Type II } \\
\text { Odontoid fx }\end{array}$ & Failure & $300 \mathrm{cc}$ & $3.94 \mathrm{~mm}$ & $\begin{array}{l}\text { R } 2.78 \mathrm{~mm} \\
\mathrm{~L} 4.42 \mathrm{~mm}\end{array}$ \\
\hline
\end{tabular}

Downloaded from http://ijssurgery.com/ by guest on April 26, 2023 
specific C1-2 fixation was 160cc. No patients had post-operative occipital neuralgia. In no cases was the $\mathrm{C} 2$ nerve root mobilized or freely visualized. No vertebral artery injuries occurred, and no new postoperative neurological deficits occurred.

The failure of one intraoperative $\mathrm{C} 1$ pedicle screw (11.1\% of patients) was noted on a 36 year male patient who presented with failure of an odontoid screw 10 months prior (Figure 6). Of note, this patient had a pedicle width less than $4.0 \mathrm{~mm}$ in diameter as measured on axial films (Figure 7). This required placement of sub-laminar wiring (Figure 8). Our results mirror $\mathrm{C} 1$ pedicle screw placement outcomes achieved through the traditional wide exposure. Thomas et al. noted 3 pedicle failures over 26 patients, $11.5 \%$ of cases. One patient in their series had small pedicles that prohibited the placement of a pedicle screw. Other failures were due to tumor involvement and non-healing unilateral fracture. ${ }^{4} \mathrm{Fo}$ cus remains on pre-operative imaging.

\section{Radiographic Outcomes}

Our series adds further depth to the technique of minimal opening. Resnick and Benzel established the technique of $\mathrm{C} 1$ pedicle screws with the help of stereotactic image guidance. ${ }^{5}$ Thomas at el proved the technique viable with lateral fluoroscopy. ${ }^{4}$ How-

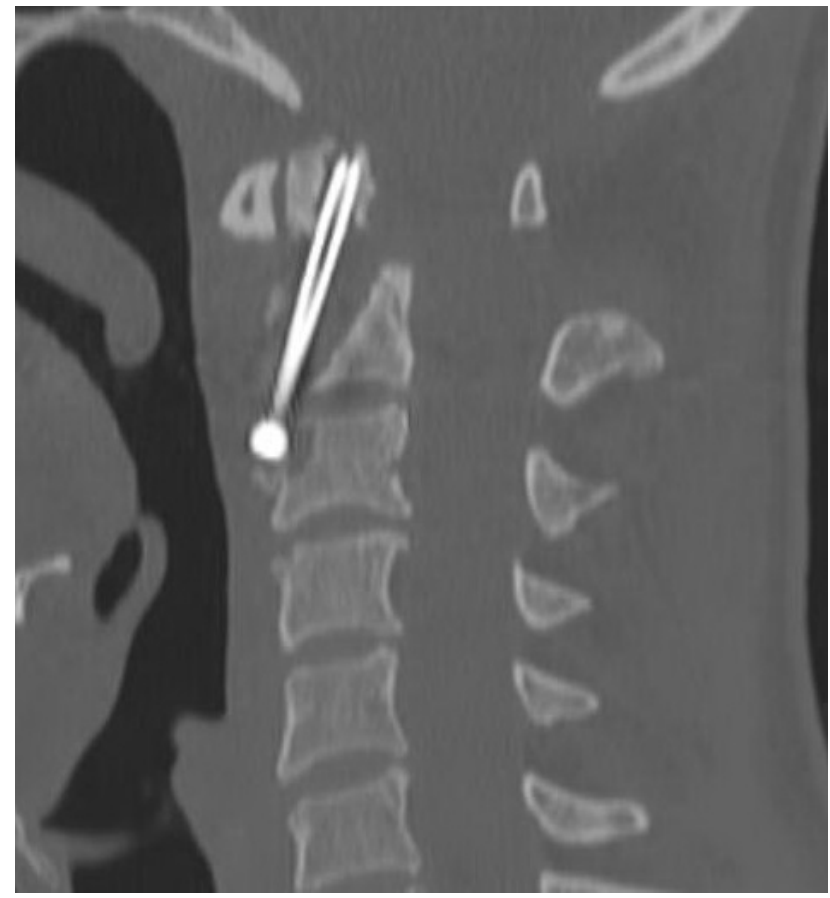

Fig. 6. Failure of Odontoid Screw Fixation at 10 months. ever, again, in their technique the authors still achieve sub-periosteal dissection of the vertebral artery over the arch of C1. This differs from our purely anatomical approximation where we leave the lateral and superior boundary of $\mathrm{C} 1$ intact using landmarks from $\mathrm{C} 2$ and the inferior ledge of the $\mathrm{C} 1$ lamina as a landing zone. We have illustrated minimal dissection with fluoroscopic guidance as safe and reasonable for the placement of $\mathrm{C} 1$ pedicle screws.

Our series shows pre-operative imaging measure-

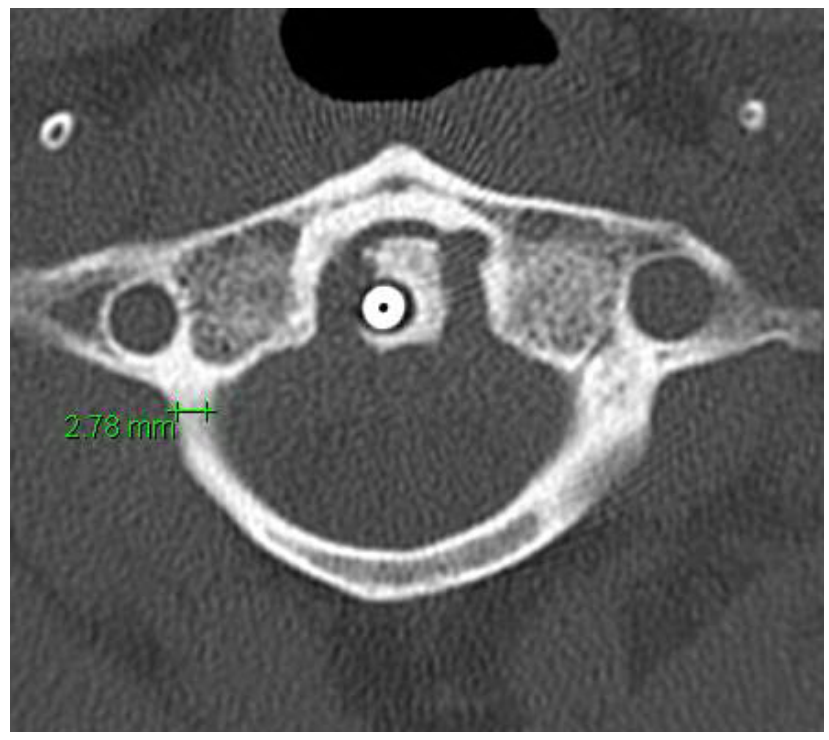

Fig. 7. Axial CT Pedicle Width Measurement on a Patient with C1 Pedicle Screw Placement Failure.

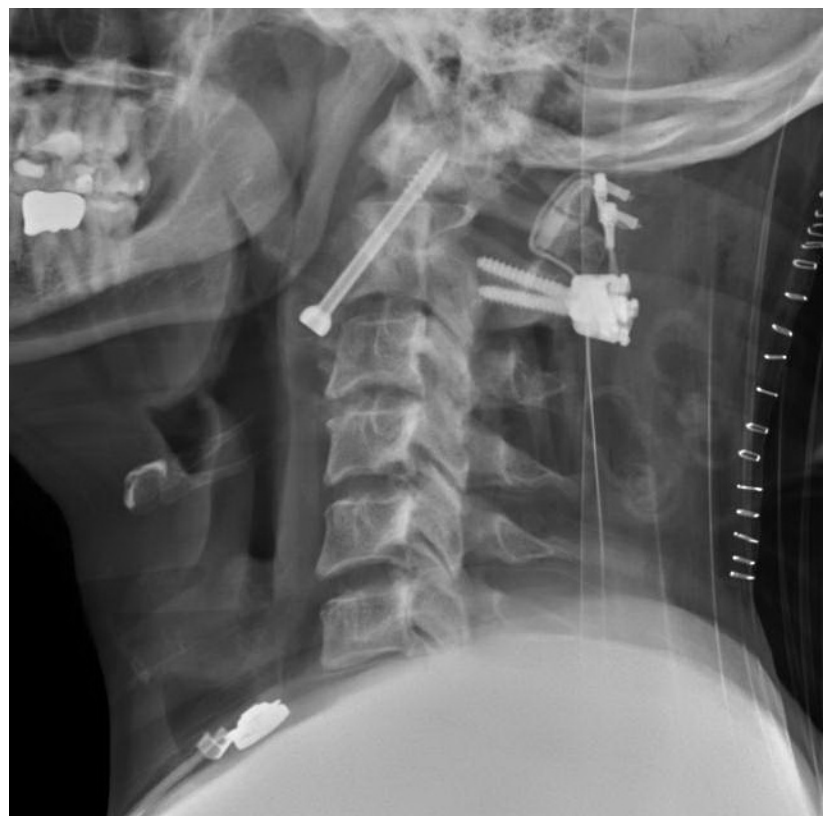

Fig. 8. C1 Laminar Wiring Following Failure to Place $\mathrm{C} 1$ Pedicle Screw.

Downloaded from http://ijssurgery.com/ by guest on April 26, 2023 
ments as radiographic validation to cadaver proven techniques of using $\mathrm{C} 2$ as an anatomic landmark for the placement of the $\mathrm{C} 1$ pedicle screws. In 2005, Yang et al, using over 50 cadavers, proved the $\mathrm{C} 1$ pedicle entry point could be safely estimated from the $\mathrm{C} 2$ lateral mass. The $\mathrm{C} 2$ lateral mass was located, on average, $1.5 \mathrm{~mm}$ lateral to the $\mathrm{C} 2$ lateral mass. $\mathrm{Au}$ thors defined the $\mathrm{C} 1$ pedicle screw entry point as directly superior to the midline of the $\mathrm{C} 2$ lateral mass and $3 \mathrm{~mm}$ below the superior rim of $\mathrm{C} 1$. Our dissection technique does not fully explore the superior rim of C1. Pre-operative measuring of appropriate height of the ring of $\mathrm{C} 1$ allows for estimation of pedicle screw landing zone as the inferior rim of the posterior arch of $\mathrm{C} 1$ given the average height in our series was $4.3 \mathrm{~mm}$.

Reliance on intra-operative anatomical landmarks requires intricate pre-operative knowledge of individual patient CT and CT angiogram imaging. The thickness of the posterior arch from the vertebral artery groove is generally $4.1 \mathrm{~mm}$; $12 \%$ of patients have thickness less than $4.0 \mathrm{~mm}$ on anatomical evaluation. ${ }^{6,19}$ Indeed in our series, 3/9 patients (33.3\%) of patients had a $\mathrm{C} 1$ arch height of less than $4.0 \mathrm{~mm}$. In $\mathrm{Ma}$ et al, through cadaver series, ten $\mathrm{C} 1$ pedicle screws were placed using measurement techniques. Echoing the Yang data, they illustrated that the center of $\mathrm{C} 2$ lateral mass was $1.51 \mathrm{~mm}$ lateral to the sagittal plane entry point for the $\mathrm{C} 1$ pedicle. This is beneficial as it places the entry point of the $\mathrm{C} 1$ screw at the thicker portion of the $\mathrm{C} 1$ pedicle. In their series, the mean rostro-caudal height of the $\mathrm{C} 1$ posterior arch at the medial one third is $3.88 \mathrm{~mm}$. At the lateral one-third of the pedicle, this increased to 4.25 $\mathrm{mm}$. The distance from the suggested screw entry point to the $\mathrm{C} 1$ anterior tubercle was $22.15 \mathrm{~mm}$, and the mean length of the screw tract was $28.55 \mathrm{~mm} .^{6}$

It is generally accepted the pedicle be at least $4 \mathrm{~mm}$ in order to burden the $3.5 \mathrm{~mm}$ pedicle screw. However, this assumption is currently evolving. Huang et al. showed that $\mathrm{C} 1$ pedicle screws can be safely placed when outer cortical height is less than $4 \mathrm{~mm} .{ }^{20} \mathrm{In}$ their series, 14 pedicles showed adequate placement of a $\mathrm{C} 1$ pedicle screw despite a pedicle diameter of less than $4 \mathrm{~mm}$; all patients had fusion at six months with no complications. ${ }^{20}$ This finding however has been met with certain debate in the European literature with questions regarding CT type and model, CT software, and homogenous population subsets. ${ }^{21}$ Further investigation is forthcoming.

\section{Biomechanical}

Biomechanical comparison of $\mathrm{C} 1-2$ posterior fixation techniques illustrated that $\mathrm{C} 1$ lateral mass screws were equally as effective as $\mathrm{C} 2$ pars screws in axial pullout strength. ${ }^{22}$ Biomechanically, $\mathrm{C} 1$ pedicle screw should be superior to lateral mass due to the increased surface area of purchase. Ma et al. showed superior pullout strength and stabilities in $\mathrm{C} 1$ pedicle screw fixation versus lateral mass screws. Bicortical purchase was required by the lateral mass screw to approximate the stability of a unicortical $\mathrm{C} 1$ pedicle screw. ${ }^{6}$ Neither $\mathrm{C} 1$ pedicle screws nor lateral mass screws performed as well as transarticular screws. For C1-2 constructs, Lapsiwala et al. showed that transarticular screws best limited lateral bending, lateral mass or pedicle screws best limited axial rotation, and cables best limited flexion/extension. ${ }^{23}$ However, the reality is that transarticular screws are not viable options in up to $20 \%$ of patients. ${ }^{3,4}$

Zarro et al directly tested the pull-out strength of $\mathrm{C} 1$ lateral mass and posterior arch screws. ${ }^{24}$ It was noted that unicortical posterior arch screws have a statistically significant superior resistance to pull out as compared to a C1 lateral mass screw, $1403 \mathrm{~N}$ as compared to $821 \mathrm{~N}$. It is important to note that inclusion criteria in this study for the placement of a posterior arch screw again was thickness of at least $4.5 \mathrm{~mm}$ in pedicle diameter. Indeed in our study, patients straddling this criteria, through a minimum of 6 month follow up, have not experienced screw pull out.

\section{Limitations}

Information was limited regarding retrospective review. Specifically, discussion of pre-operative planning was not available. Specific patient indicators for the placement of $\mathrm{C} 1$ screws as opposed to another construct were not considered. Outcomes related to anterior approach surgery were not considered. No direct objective comparison of patient related disability scores or patient related outcomes is achieved between $\mathrm{C} 1$ lateral mass and C1 pedicle screws. Despite a relatively robust cranio-vertebral series isolated 
C1-2 fusion represented only 9 cases over a six-year period. Follow up beyond that time frame is not possible. There are no direct patient based outcome measures. Measurement of radiographic values was performed using the measurement tool provided on the image interface. Radiographic review was performing by one neurosurgeon not involved in the operative care of the patient. Approximation beyond one decimal point of value was not possible on certain interfaces. Regardless, our series adds to the literature by showing a minimal exposure technique as a safe and effective.

\section{Conclusion}

Our study directly adds to the literature by supporting a minimal dissection of $\mathrm{C} 1$ arch in the placement of $\mathrm{C} 1$ pedicle screws with both radiographic and clinical validation. This does not assert the superiority of our technique to existing methods. Rather it provides a safe alternative to the overall goal of providing a stable and safe construct between the atlas and the axis. It serves as a technical report for a more minimal dissection technique.

Usage of fluoroscopic guidance and C2 landmarks allows for the safe and effective placement of $\mathrm{C} 1$ screws without dissection of the superior and lateral portions of $\mathrm{C} 1$. This avoids $\mathrm{C} 2$ nerve root manipulation or sacrifice, reduces bleeding associated with the vascular plexus on the lateral portion of the posterior arch of $\mathrm{C} 1$, and leaves the third segment of the vertebral artery unexplored. Pre-operative review of imaging is critical in the placement of C1-C2 instrumentation.

\section{References}

1. Finn MA, Apfelbaum RI. Atlantoaxial transarticular screw fixation: update on technique and outcomes in 269 patients. Neurosurgery. 2010 Mar;66(3 Suppl):184-92.

2. Jacobson ME, Khan SN, An HS. C1-C2 posterior fixation: indications, technique, and results. Orthop Clin North Am. 2012 Jan;43(1):11-18, vii.

3. Mummaneni PV, Haid RW. Atlantoaxial fixation: overview of all techniques. Neurol India. 2005
Dec;53(4):408-15.

4. Thomas JA, Tredway T, Fessler RG, Sandhu FA. An alternate method for placement of C-1 screws. J Neurosurg Spine. 2010 Apr;12(4):337-41.

5. Resnick DK, Benzel EC. C1-C2 pedicle screw fixation with rigid cantilever beam construct: case report and technical note. Neurosurgery. 2002 Feb;50(2):426-8.

6. Ma X-Y, Yin Q-S, Wu Z-H, Xia H, Liu J-F, Zhong S-Z. Anatomic considerations for the pedicle screw placement in the first cervical vertebra. Spine. 2005 Jul 1;30(13):1519-23.

7. Bridwell K, DeWald R. The Textbook of Spinal Surgery. 3rd Edition. Lippincott Williams and Wilkins. 3rd ed. Philadelphia: Lippincott Williams and Wilkins.

8. Dickman CA, Sonntag VK, Papadopoulos SM, Hadley MN. The interspinous method of posterior atlantoaxial arthrodesis. J Neurosurg. 1991

Feb;74(2):190-8.

9. Stock GH, Vaccaro AR, Brown AK, Anderson PA. Contemporary posterior occipital fixation. Instr Course Lect. 2007;56:319-28.

10. J Harms RPM. Posterior C1-C2 fusion with polyaxial screw and rod fixation. Spine.

2001;26(22):2467-71.

11. Yeom JS, Kafle D, Nguyen NQ, Noh W, Park K$\mathrm{W}$, Chang B-S, et al. Routine insertion of the lateral mass screw via the posterior arch for $\mathrm{C} 1$ fixation: feasibility and related complications. Spine J Off J North Am Spine Soc. 2012 Jun;12(6):476-83. 12. Mummaneni PV, Lu DC, Dhall SS, Mummaneni VP, Chou D. C1 lateral mass fixation: a comparison of constructs. Neurosurgery. 2010 Mar;66(3 Suppl):153-60.

13. Tan $M$, Wang $H$, Wang $Y$, Zhang G, Yi P, Li Z, et al. Morphometric evaluation of screw fixation in atlas via posterior arch and lateral mass. Spine. 2003 May 1;28(9):888-95.

14. Qian L-X, Hao D-J, He B-R, Jiang Y-H. Morphology of the atlas pedicle revisited: a morphometric CT-based study on 120 patients. Eur Spine J Off Publ Eur Spine Soc Eur Spinal Deform Soc Eur Sect Cerv Spine Res Soc. 2013 May;22(5):1142-6.

15. Lee MJ, Cassinelli E, Riew KD. The feasibility of inserting atlas lateral mass screws via the posterior arch. Spine. 2006 Nov 15;31(24):2798-801. 
16. Christensen DM, Eastlack RK, Lynch JJ, Yaszemski MJ, Currier BL. C1 anatomy and dimensions relative to lateral mass screw placement. Spine. 2007 Apr 15;32(8):844-8.

17. Pan J, Li L, Qian L, Tan J, Sun G, Li X. C1 lateral mass screw insertion with protection of $\mathrm{C} 1-\mathrm{C} 2$ venous sinus: technical note and review of the literature. Spine. 2010 Oct 1;35(21):E1133-1136.

18. Lin JM, Hipp JA, Reitman CA. C1 lateral mass screw placement via the posterior arch: a technique comparison and anatomic analysis. Spine J Off J North Am Spine Soc. 2013 Nov;13(11):1549-55. 19. Ebraheim NA, Xu R, Ahmad M, Heck B. The quantitative anatomy of the vertebral artery groove of the atlas and its relation to the posterior atlantoaxial approach. Spine. 1998 Feb 1;23(3):320-3.

20. Huang D-G, He S-M, Pan J-W, Hui H, Hu H$\mathrm{M}, \mathrm{He} \mathrm{B}-\mathrm{R}$, et al. Is the $4 \mathrm{~mm}$ height of the vertebral artery groove really a limitation of $\mathrm{C} 1$ pedicle screw insertion? Eur Spine J Off Publ Eur Spine Soc Eur Spinal Deform Soc Eur Sect Cerv Spine Res Soc. 2014 May;23(5):1109-14.

21. Letter to the Editor concerning "Is the $4 \mathrm{~mm}$ height of the vertebral artery groove really a limitation of $\mathrm{C} 1$ pedicle screw insertion?" (by Da-Geng Huang, Si-Min He, Jun-Wei Pan, et al. Eur Spine J, 2014, 23(5):1109-1114) - Springer. [cited 2014 Nov 29]; Available from: http://link.springer.com/article/10.1007/s00586-014-3433-5/fulltext.html

22. Hott JS, Lynch JJ, Chamberlain RH, Sonntag
VKH, Crawford NR. Biomechanical comparison of C1-2 posterior fixation techniques. J Neurosurg Spine. 2005 Feb;2(2):175-81.

23. Lapsiwala SB, Anderson PA, Oza A, Resnick DK. Biomechanical comparison of four $\mathrm{C} 1$ to $\mathrm{C} 2$ rigid fixative techniques: anterior transarticular, posterior transarticular, $\mathrm{C} 1$ to $\mathrm{C} 2$ pedicle, and $\mathrm{C} 1$ to $\mathrm{C} 2$ intralaminar screws. Neurosurgery. 2006 Mar;58(3):516-521; discussion 516-521.

24. Zarro CM, Ludwig SC, Hsieh AH, Seal CN, Gelb DE. Biomechanical comparison of the pullout strengths of $\mathrm{C} 1$ lateral mass screws and $\mathrm{C} 1$ posterior arch screws. Spine J. 2013 Dec 1;13(12):1892-6.

\section{Disclosures}

The authors declare no relevant financial disclosures.

\section{Corresponding Author}

Richard Menger, LSU Health Sciences Center - Shreveport, Department of Neurosurgery, 1501 Kings Highway, PO Box 33932, Shreveport, LA, 71130. richard.menger@gmail.com.

Published 12 August, 2015.

This manuscript is generously published free of charge by ISASS, the International Society for the Advancement of Spine Surgery. Copyright @ 2015 ISASS. To see more or order reprints or permissions, see http://ijssurgery.com. 